\title{
Fidalgos e vaqueiros: de monumento antropológico a ode do universo agropastoril
}

\section{Jorge de Souza Araujo (UEFS)}

Destacada figura na alvorada da poética modernista na Bahia, ao lado de Godofredo Filho, Carvalho Filho, Sosígenes Costa, Alves Ribeiro e poucos outros, Eurico Alves é "poeta baiano salpicado de orvalho e tenro cocô de cabrito", conforme entoou Manuel Bandeira num poema-carta, "Escusa”, desculpando-se por não poder atender ao convite de visitar a Bahia. Aclamado bardo das instâncias épicas e líricas da região de Feira de Santana, Eurico Alves ou Eurico Alves Boaventura, nascido em 27 de junho de 1909 e falecido em 4 de julho de 1974, aposentado como juiz de Direito em Salvador, fez inquieto percurso no grupo reunido pela revista Arco e Flexa, deixando impressa uma poesia de apreciáveis recursos.

Mas é como autor de um texto volumoso e denso, fruto de anos de pesquisa e perlaborção exegética que EAB também irá merecer a consideração de estudiosos da literatura baiana, particularmente na fixação memorial, histórica, sociológica e antropológica da zona pastoril de Feira de Santana e arredores, em que a vida sertaneja, criteriosamente contraposta à leseira patriarcal da zona litorânea ou dos engenhos de açúcar, ganha aparências de harmonia e equilíbrio aristocráticos e de ofícios vaqueanos. Data de 1953 a introdução de Fidalgos e vaqueiros, que Wilson Lins equipara ao Casa grande \& senzala, de Gilberto Freyre, seguidamente objeto de cotejo e antiglosa críticos por parte do estudioso baiano. O livro, porém, só conheceria uma edição em 1989, publicado pelo Centro Editorial e Didático da Universidade Federal da Bahia. 
Com um estilo dialógico fundindo fronteiras historiográficas e literárias, que mesclam predicados entre a ciência e a arte da palavra, Eurico Boaventura estende margens de ponderação estética ao seu Fidalgos e vaqueiros, modelo de fusão historiográfica e sociológica à luz de diferentes radiações de linguagens e moldes. Cada capítulo (e são 11, ao todo), dialoga com epígrafes extraídas de obras literárias, epígrafes servidas como motes pretextuais e intersemióticas para o desenvolvimento interativo do texto, antecipando o seu percurso. No corpo dos capítulos, seguindo um rito dialógico que enriquece o relato, o autor faz circular o pensamento de escritores e poetas, nacionais ou não, perseverando nas sentenças e axiomas, seja de um Castro Alves — "No chão da história o passo teu verás" — , ou de um Lope de Vega: "que basta que me escuchen las estrellas".

No prefácio ao livro, Wilson Lins o tem na condição de anteparo a algumas das teses enunciadas por Gilberto Freyre em Casa grande \& senzala, sobretudo quanto ao divórcio de modelos de sociedades apresentados pelos dois autores. E sugere Lins o título que, ao seu ver, melhor empalmaria a qualificação temática da obra: Aristocracia dos currais. Iniciada em 1952, concluída em 1963 e somente publicada em 1989, a pesquisa exaustiva de Eurico resulta numa réplica inconsciente ao Casa grande \& senzala, constituindo-se sua aristocracia curraleira em classe laboriosa e suarenta, avessa ao conforto patriarcal, que delegava o trabalho exclusivamente ao braço escravo.

A introdução de Fidalgos e vaqueiros é uma advertência de modéstia e, ao modo de Luís da Câmara Cascudo, representa fidelidade ao cosmo sertanejo e suas idiossincrasias, incluindo estilo e linguagem, visão de mundo e identidades ideológicas. $\mathrm{O}$ autor recusa ao livro a consideração historiográfica, insinuando tratar-se não de um "livro de história, porque não quis sê-lo". Tampouco é visto como interpretação sociológica, apenas testemunho, uma história e visão particulares do universo agro-pastoril sertanejo. Historiador acossado pela expressão telúrica das éclogas, ressaltando "o amor com que foram escritas estas páginas" (Cit., 12), autocentrado e auto-referenciado no relato memorial, Eurico Alves Boaventura declara e se felicita com base apenas na força e peso do próprio relato, objeto a que se devota com a paixão dos amadores. Além de Ortega e Lope, o autor recita, apropriando-se, textos clássicos, renascentistas, modernos e seus contemporâneos, escalando os tipos mais diversos de autores, do Camões épico/lírico ao tradicionalista Gustavo Barroso, de Bocage ou Bilac a Nina Rodrigues ou Braz do Amaral.

Eurico não se furta aos veios metafóricos na construção de seu texto científico. Fala do eco dos aboios chegando aos ouvidos, metaforizando imagens telúricas, da 
mesma forma que cuida do texto como obra de reação ao mal-entendido bistórico da consideração de apenas dois Brasis, o do Norte (ou Nordeste) cristalizado por Gilberto Freyre e Roger Bastide, com modelos de engenho e canavial e senhores escravistas e voluptuosos, cotejado com um Brasil do Sul, povoado por índios, desbravadores e pioneiros. O sertão pastoral sobre o qual se debruça Eurico Alves Boaventura é distinguido com novas enunciações e redirecionamento de olhares. Fidalgos discute ainda a geografia fisiográfica e humana, o Recôncavo e o Sertão, com seu polígono de secas, caatingas, pastoreio, distância da Bahia litorânea, para isso se municiando de um verdadeiro aluvião bibliográfico, tantos livros à mão cheia roteirizando a discussão e o debate em torno das relações discrepantes dos costumes do litoral canavieiro e o sertão integrado. Exemplo do estilo cunhado por Eurico Alves Boaventura em sua obra, estilo com direito a analogias bizarras e sutis aliterações: "Morre o Recôncavo, quando as espátulas do canavial cedem lugar ao flácido flabelar festivo do capinzal, das capineiras". (Cit., 17)

A afetividade orgulhosa do autor de Fidalgos e vaqueiros trescala maniqueísmos ainda mais sutis, traduzindo diferentes interpretações para diferentes costumes entre o canavial e a caatinga: 'Já se não ouvem gritos histéricos de feitores sádicos, mas sim a melopéia do aboiado, conduzindo a vida e o rebanho para a alegria do sertão imenso. Imenso como um coração". (Cit., 17) Outras mostras estilísticas fazem emergir um maneirismo típico de poeta analisando situações descritas no relato de História Social: "O desenvolvimento da vida social brasileira expandiu-se em etapas, aos gaguejos da sua economia abandonada pela metrópole”. (Cit., 17) A sisudez historiográfica cede o passo ao personalismo da linguagem e EAB fala livre do "tagarelar dos chocalhos dos currais" (Cit., 21). Arrisca-se o autor a insólitas especulações sobre os cruzamentos étnicos, mais uma vez adiantando-se a aliteração num exercício de gozo logomáquico - "leves leques lépidos lentamente". (Cit., 30) Não é à toa que o relato é desenvolvido em primeira pessoa, sob o impacto das impressões e memórias retidas do observador, tornado historiador social, assim como o foram também um Alcântara Machado ou um Catulo da Paixão Cearense, e ainda que o vezo do poeta à historiografia se faça acompanhar do rigor metodológico que perfila desde Oliveira Viana a Capistrano de Abreu, a Toynbee, Werneck Sodré, reunidos a Bilac, Juvenal Galeno, Mário Palmério, romancista de Vila dos Confins...

Pelo estilo algo grandiloqüente, neo-barroco, ou rococó, Eurico Alves Boaventura habilita seu texto a uma historiografia social com tinturas de sociologia literária. Veja-se, a propósito, como encerra o capítulo I de Fidalgos e vaqueiros, intitulado "Nômades e vaqueiros": 
Pela carne suja de pó das estradas ermas, no arabesco ruivo e disperso que os cascos fortes da cavalhada fizeram, nas garatujas que o rastro dos bois, dos carneiros e dos bodes gizaram, lê-se o abecedário para a primeira página desta crônica esquecida. Viva, porém. E de mérito absoluto. (Cit., 39)

Em que pese a esquemática visão casagrandeana de seu ensaio - que sempre se irá referir ao genérico pitoresco de indiada ou negraria - Eurico Alves Boaventura revela uma singular apreensão da realidade do pastoreio nordestino e sertanejo. Melhor se apura o Fidalgos e vaqueiros no aparato formal da linguagem e do estilo, reforçados ambos pelo dialogismo com autores e textos, no corpo do relato e nas epígrafes, pretextando situações heróicas associadas ao homem do interior, especialmente o vaqueiro. O ensaísta tende a dissolver conflitos presumíveis na operação de conquista e bandeiras da Bahia sertaneja. EAB entoa louros à civilização do couro, recorrendo à memória histórica, lírica e épica, socializando as imagens sensoriais à moda de Proust. Seu tributo a-crítico à catequese regeneradora segue a lógica do oficialismo históricotriunfalista. Ao tempo em que sumaria Canudos como recusa ao espírito religioso, compreendendo-o como negativa de perturbação mística e tachando-o de "sintoma de incultura, manifestação da ignorância da massa amorfa espiritualmente" (Cit., 62), a obra também o nega como movimento espontâneo de insurgência contra o abandono a que os sertanejos se viram expostos.

Fidalgos e vaqueiros dialoga também com a lenda e a narrativa do maravilhoso e folclórico de espírito ibérico. Reconta o pacto com o Diabo e o embuste armado por Romão Gramacho Falcão construindo a igreja matriz de Humildes com o dinheiro endemoninhado, variando a história narrada por Silva Campos, com os mesmos recursos do ardil de Romão, mas para a edificação da igreja de Nossa Senhora em Oliveira dos Campinhos... EAB incorre em notórios riscos da impropriedade antropológica (na ânsia de reduziir o número de escravos nos sertões, habitados por "famílias de pele alva, gente limpa de sangue" (Cit., 81), deplorando grupos étnicos que não se misturam, contrariando assim a tese da miscigenação natural. E sucumbe ao inconsciente preconceituoso, protestando contra os que "não aceitam melhoria para o seu criatório estes negros mantendo apenas as primitivas espécies de animais" (Cit., 85). Neles acusa o historiador um "adiantado complexo de inferioridade, roendo-lhe a vida, na coloração noturna da pele" (Cit., 85) e, sem maior base antropológica, decreta ser "fraca, repita-se, a contribuição do negro no cruzamento sertanejo". (Cit., 87)

A despeito destas e outras tantas incorreções de análise, Fidalgos e vaqueiros assinala um fulgurante potencial de estudo dos costumes sertanejos na Bahia a partir do 
micro-cosmo de Feira de Santana e o seu entorno agro-pastoril. É livro que inscreve definitivamente Eurico Alves Boaventura na galeria de nossos melhores exegetas, argumento que reforça a obrigatoriedade da sua leitura, essa que se dá acompanhada e dialógica com importantes contributos da literatura baiana e brasileira.

A eloquência das imagens reverberam repercussões sinestésicas e metafóricas no texto e no discurso. Ousadias no repertório vocabular reagem às análises de circunstâncias pouco atraentes da vida econômica e social. Imagens surpreendentes pelo ineditismo e pelo uso bizarro e personalíssimo não impedem a transfiguração também equivalente de uma nítida visão casagrandeana, conjugada com alguns mitos aristocráticos do bom senhor... A obra de Eurico Alves Boaventura deixa, por vezes, de ser história social para tornar-se elogio, ode pastoral, memória discursiva e a-crítica recoberta de afetividade ou do sujeito na crítica, formulando e reformulando conceitos, indiciando marcas dispersas de leitura bibliográfica e leitura de mundo. Aí cabem os maneirismos do historiador memorialista submetido, como Câmara Cascudo, ao garimpo fruidor das superstições e dos costumes: "a madeira-de-lei se eterniza no ar. E se perpetua no chão. E sempre extraída no minguante da lua, para ficar isenta de bichar". (Cit., 106, grifo nosso)

História social e memória individual e coletiva evidenciando sensibilidade telúrica e consciência ecológica, Fidalgos e vaqueiros reflete e projeta uma verdadeira revisão de valores entre o Recôncavo e o Sertão, filtrando uma narrativa de fundação, refundindo a música onomatopeica dos capinzais curraleiros e o ser sertanejo, percebido antes do território, o sertão como origem, condição sócio-econômica e étnica, assunção identitária permanentemente reelaborada. Talvez em conseqüência disso freqüentemente Eurico Alves Boaventura se incumba de corrigir (ou emendar, melhor dizendo) observadores ou informações que considera aligeiradas. Sua obra é elogio ao pastoreio, mas também à caatinga, à terra ubérrima, ao rio viçoso e piscoso, tudo influindo na têmpera do indivíduo pastoril e sertanejo, vaqueiro e senhor da casa-da-fazenda. Numa expressão, trata-se de uma "civilização de atitudes que são plágios sociais da catinga" (sic, Cit., 110) ou o "chão cru" (que) "fez homens rijos, rígidos e retos", produtos de "verticalidades de sol (...) homem e terra sem disjunção". (Cit., 110)

O historiador e memorialista se confunde com o sociólogo, o geógrafo e o antropólogo, igualmente sugestionando pelo pinturesco folclórico das crendices populares: "Caído o umbigo, Ioiô, o próprio Ioiô ia enterrá-lo junto ao mourão da porteira do curral, para que os ratos não no roessem. Fazia mal medonho rato comer umbigo de menino: - Viraria ladrão o pequerrucho" (Cit., 111). O senso de proporção e acuidade 
acadêmica também acompanha o supersticioso, com o narrador registrando citações com empenho filológico, grafando-as conforme o original, tal como se vê na bizarra anotação de Fernão Cardim de que "a terra he algum tamto malencolica" (apud Cit., 120).

Retrato da família senhorial, pastoril, seus solares, bens e costumes, Fidalgos e vaqueiros realiza a notação impressionista da civilização do couro, civilização sertaneja, do campo e da casa, com ressaltos antropológicos, a exemplo da referência à "casa sertaneja, a popular sobretudo, mas também o solar", compreendidos como "lição indiscutível de ecologia". (Cit., 130) Eurico Alves Boaventura é pintor da paisagem humanizada, ainda que áspera e hostil, do sertão, do ambiente pastoril. E do indivíduo, o fidalgo pastor, visto por Eurico como um plagiador de Deus (Cit., 132). O mito do bom senhor, é claro, obnubila a visão crítico-historiográfica, fazendo o narrador acreditar numa falsa noção de democracia étnica na relação Casa Grande \& senzala no interior do ciclo sertanejo. Por esse viés "os escravos, os agregados, era como se no próprio solar morassem". (Cit., 133) O interior principesco dos solares, entretanto, é descrito com altaneria maneirista típica do cronista afetivizado pela lembrança do antigo fausto. Eurico Alves Boaventura ressalta os possuíres domésticos dos fidalgos, filiando-se a Proust na recolha da memória afetiva, inclusive dos objetos. Então o relato ganha contornos e relevos de um colorido pictórico peculiar.

Com base em indicações de lacunas bibliográficas, o texto ressalta o papel dos tropeiros conduzindo mercadorias e estendendo a civilização aos sertões aduncos, auxiliando o fazendeiro nas entradas e permanências dos sítios do interior, expandindo o ofício de desbravamento bandeirante. Mas Eurico Alves Boaventura faz a ressalva: "era a cobiça e era a ganância o motivo (sic) de tanta aventura na voragem verde dos ignorados caminhos do sertão bruto". (Cit., 140). O narrador, na ganga de erigir em ícones os elementos estruturadores da civilização sertaneja, se concede hipérboles ufanistas: "Fizeram sozinhos o mapa da Pátria o vaqueiro, o fazendeiro e o tropeiro". (Cit., 141) Também se concede ilações chistosas, apodando (com a maior sem-cerimônia) Tollenare de visitante comercial das Arábias e falsário portador de jóias falsas para presentes (Cit., 148). O poeta se traveste, ocupado em descortinar animicamente a história social, defendendo a hipótese de que "a história de uma sociedade tem alma brasileira". (Cit., 157)

No cotejo civilização da cana-de-açúcar versus civilização do pastoreio, Eurico Alves Boaventura tudo faz para demonstrar a superioridade da segunda. Para tanto, o texto apela para exemplos da Literatura e da Política, ilustrando a propósito da titularidade literária de Castro Alves: "Nem a poética de Castro Alves tão pouco traz 
gosto de melaço de engenho. Tem asperezas de estradas sertanejas a sua poesia, como pureza de orvalho na grama da malhada, manhãzinha, ou graças de luzes matutas". (Cit., 178) Os feitos heróicos são recheados de citações épicas (especialmente Camões). O narrador contesta como anacrônicas as teses de Gobineau, mas é o mesmo que reveste de melancolia nostálgica sua crítica ao rumo do presente sem o monumento da casa grande: "hoje, com a degradação dos costumes e a morte da tradição, quase que não se cuida de exemplo”. (Cit., 185) Como Euclides da Cunha, Eurico Alves Boaventura percorre os mais distintos ramos das ciências, interdialogicamente, indo da História à Sociologia e desta à Antropologia, à Biologia etc., tudo perseguindo em proveito de suas teses. Incursiona também pela Genética e pela re-orientação da formação social brasileira, contestando conceitos de heranças colonizadoras de degredados, e antes protestando: "tudo quanto se diz do degredado, do pirata, que fecundaram as índias ou as negras na Colônia, é mera adivinhação. Restabeleça-se a verdade no caso" (Cit., 185), ocupando-se em "desmentir a lenda inconsistente de origem chinfrin para a nossa gente". (Cit., 185)

Eurico Alves Boaventura atenta alentadamente para a carnação morena e fácil das mulheres primitivas favorecendo, com a oferta generosa, a floração da sinfonia incontestável do desejo entre os colonos famintos e sedentos: "Índias cor de crepúsculo, cuja nudez modesta era uma carícia para os olhos saudosos dos homens sem mulheres brancas para a volúpia das noites misteriosas do sertão (...) Mulheres nuas aromadas da água virgem dos rios lépidos, ou de folhas machucadas...” (Cit., 188) O historiador social se insurge contra a propalada degenerescência, por ele atribuída à obra de cuidadosos jesuítas ocupados na missão da catequese - conseqüentemente avessos ao que estimulava Camões, Canto 9, estrofe 83 (citado por Eurico Alves) acerca dos favores da Vênus inflamadora de prazeres:

Melhor é experimentá-lo que julgá-lo, Mas julgue-o quem não pode experimentá-lo (Cit., 189)

Com frequência, Fidalgos e vaqueiros deriva para ilações historiográficas, sociológicas, antropológicas, por vezes confundindo os intentos formais do capítulo e dando margem a um amontoado de teses que, se não prejudicam o conjunto por suas peculiaridades e agudezas analíticas, certamente confundem o leitor sobre o percurso objeto da obra. Mas em que pese o freqüente e difuso crepitar dessas intervenções, e da descrição poética (sem base historiográfica) dos Alencares e Gonçalves Dias, é como 
poeta que Eurico Alves Boaventura descortina o processo da mestiçagem brasileira, distinguidamente nos recantos do interior dos sertões onde "o ventre da índia foi o horizonte donde eclodiu o luar das peles alvas dos mestiços da primeira hora e cujo reflexo incendiaria e incendeia certos cantos da catinga (sic), ainda hoje, no crepúsculo moreno da mestiçagem de cobre”. (Cit., 201)

Todavia, o agudo historiador social, combinado com o memorialista e o sensível poeta, por vezes incorre na imprevisível justificação dos atos e torturas escravocratas, compreendendo índios e negros como "defeitos que se compreendem no tempo e no estalão cultural de muitos”. (Cit., 203) Eurico Alves Boaventura aventura-se, ainda, pela listagem caprichosa de ramos genealógicos, descrevendo troncos familiares e ramificações pelo sertão pastoral. Evoca, por exemplo, os Carneiro, os Pamponet e Suzart, de ontem, e os Miranda e Boaventura de hoje, fazendo especial referência a essas famílias, extensivas especialmente à região de Baixa Grande. Tangencia também a formação de um sem-número de filhos naturais, geralmente frutos de filhos-famílias com as negras da Casa Grande e a precoce despedida da donzelice até com as cabrochas prostitutas dos Becos do Bom e Barato (em Feira de Santana, entre as ruas Direita e da Aurora). A narrativa incursiona pela graça maliciosa, destacando que "todo rapaz adolescente era uma reticência noturna presa àquelas belezas a preço reduzido". (Cit., 215) Nesse campo fenomenológico, a quebra do cabresto também se fazia com as cabras, as mamotas e as toras de bananeiras...

O ensaio memorial de Eurico Alves Boaventura registra ainda a convenção parental do casamento entre primos, as fugas do moço humilde para casar-se com a Sinhá, contrariando as coerções patriarcais e outros modelos de comportamento na sociedade de base pastoril. O narrador reforça o aporte eugênico das etnias entrecruzadas e os hábitos de uma alimentação farta e variada, de acordo com os produtos do pastoreio, mais o mel e a caça abundante. $\mathrm{O}$ estilo boaventurano destila um temperamento de literariedade no relato, aproximando o discurso científico das fronteiras com a Poética, não apenas pelas numerosas remissões dialógicas história/ literatura, como pela própria vestimenta do texto narrativo revestido de poeticidade e sincronia. Dessa forma, manifestando sua perspectiva de historicidade mediante reverberação telúrica, o narrador conclui ser "a vida-pastoril", no passado, um roteiro de "paisagem em movimento". (Cit., 251) A vida campesina do sertão é enaltecida em ode, deleitando-se o exegeta numa linguagem de descrição do ambiente como algo que dessedenta o nativo, embevecido com a natureza íntima da paisagem, feliz ecologista natural e panteísta, "bebendo água de caldeirão, onde até as cobras desalteravam a sede”. (Cit., 253) 


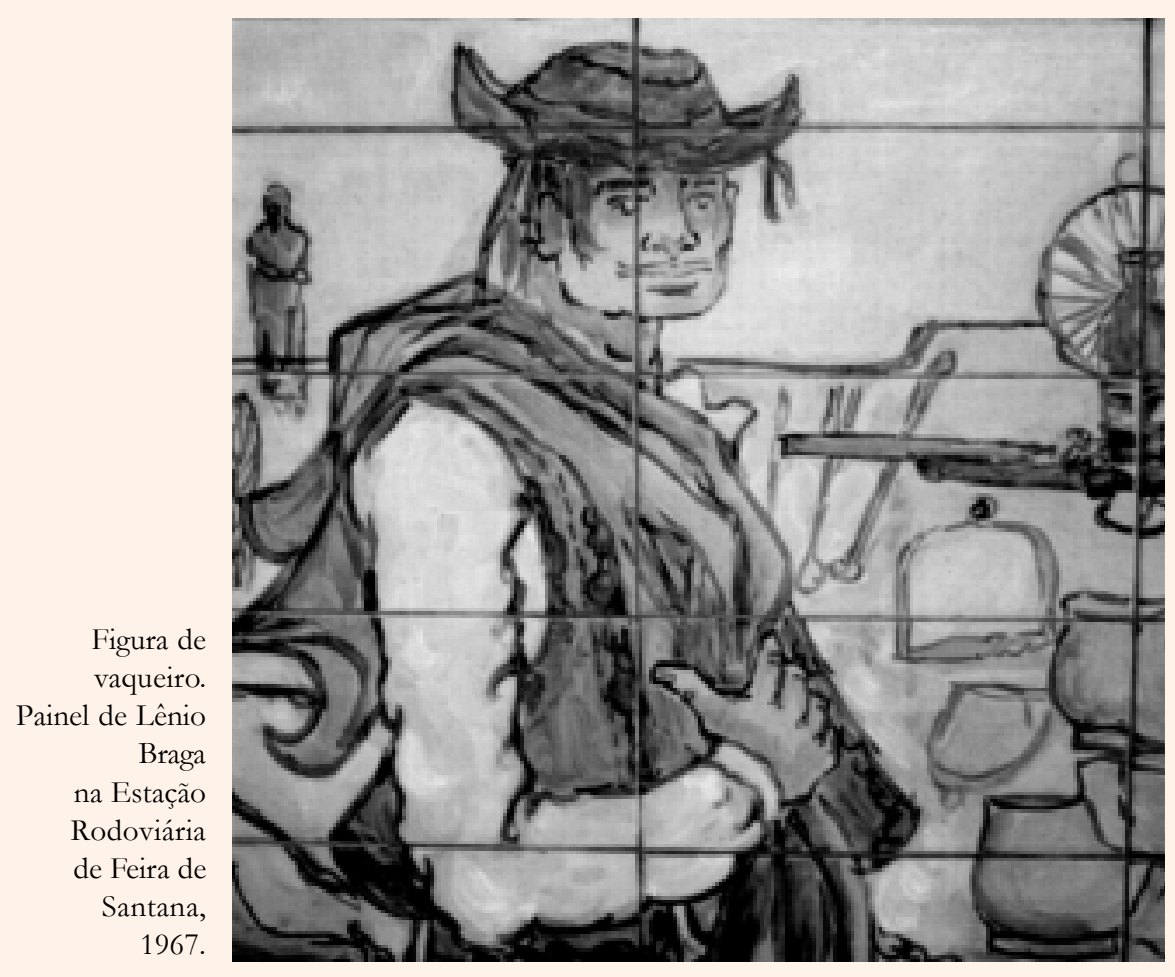

Nessa faina de exalçamento da fidalguia pastoril, não raras vezes Eurico Alves Boaventura exagera no debique gorduroso destinado à aristocracia canavieira, opondo-lhe costumes maneiristas de dengosa atitude no desprezo ao trabalho, atributo, ao ver do narrador, exclusivo dos senhores e vaqueiros do universo sertanejo. O senhor de engenho aparecerá, então, como preguiçoso e sonolento que "enxudiava-se na rede, a boca babando açúcar de todas as formas e de todo canto, envolto naquela preguiça dos donos, dos senhores". (Cit., 258, grifo do autor) Fidalgos e agregados sertanejos, ao contrário, são distintivos, enérgicos, viris para o trabalho, o empenho e a lida, desconhecendo rede de tucum e descanso pueril, totalmente avessos a luxos e ostentações, representando "apenas força e destreza de que precisa para a vida". (Cit., 260) Vaqueiros e fidalgos (ou seja: trabalhadores e seus senhores), plenamente adaptados ao meio, como o meio reagem e atuam, sobretudo o vaqueiro, bruto, rudo, simples (Cit., 260) como o animal, o cavalo, a que se liga, completando a imagem de "centauro bronco" de que falava Euclides. Tal destemor e tal destreza realizam um perfil épico, ou, como diz o próprio Eurico: "Há estrofes rotas de uma epopéia, que a vida escreveu”. (Cit., 262)

Por isso o autor de Fidalgos e vaqueiros ressalta no discurso memorial os heróis pastoris, destacando-se o vaqueiro, o cavalo e o boi, este último especialmente cumulado das formulações épicas já consagradas no ciclo do boi maravilhoso (misterioso, mandingueiro), celebrado nas gestas sertanejas da literatura de cordel, que cumpre 
eficazmente a saga de encantamento e do maravilhoso, homens, bois e cavalos enfeixados nos mesmos lances heróicos que remontam à tradição cavaleiresca medieval e entoados pelos aedos populares. Ao lado desse ciclo heróico, a obra de Eurico Alves Boaventura destaca o valor agregado das ervas medicinais encontradiças no campo sertanejo (poaia cura bronquite, sabugueiro cura sarampo etc.), além de outros costumes e crenças do interior, alguns usos bem bizarros como bofe de lagartixa, banha de ema, leite de cerva e outras mezinhas para curar todos os tipos de doenças. Daí o livro passa à alimentação e ao tempero, origem das comidas, o gosto da pimenta e do dendê, as comidas igualmente bizarras como o jacaré, a jibóia e a gia, consagrados nos influxos étnicos (índio e negro), sua repercussão nos pratos e no jeito de prepará-los, mais os usos de folhas mateiras para aguçar sabores e apetites: salsa, coentro, alface, bredo, beldroega, língua-de-vaca, quioiô, taioba. O bom uso dos produtos do mato fortalece o sabor das comidas na paisagem pastoril e despertam a libido, intensificada pela condução descritiva de comidas e temperos no livro.

Semelhante a Euclides, Eurico cita outras referências antropológicas, e não se esquiva em pontificar ludicamente o estilo com evocações memoriais, proustianas, incluindo lembranças domésticas as mais remotas e nos mínimos detalhes. É como se o historiador não fizesse renunciar o poeta, anotando seguidas aliterações preciosistas com algum sabor de reminiscência tipicamente Cruz e Sousa: "Sabia e sabe, como ninguém, fazer esflorar em flácidos e fracos flocos, fartos de flores fulvas o doce de leite de calda". (Cit., 260)

Além de percorrer a história social do sertão visto desde Feira de Santana e intervindo mediante rasgos de eloqüência antropológica amadora, o livro de Eurico Alves Boaventura vale talvez mais eficazmente por sua característica memorial, memória sociológica combinada com a afetiva e pessoal do autor, conquanto predomine a visão do solar fidalgo, da casa grande agro-pastoril sertaneja. Essa visão, aliás, determina o penhor de Eurico assinalando o desarranjo concertado pela Abolição nos moldes em que ela se deu no Brasil: "Não melhorou a mesa do pobre com a libertação do escravo. Teve a liberdade, mas permaneceu preso ao tronco da economia". (Cit., 289, grifo do autor) Delicioso trecho comenta o embate natural enfrentado pela fraqueza do sexo viril (Cit., 294).

Eurico Alves Boaventura por certo subscreveria (até porque pratica) a sentença que cita de Roger Bastide, segundo a qual "o sociólogo que quiser compreender o Brasil não raro precisa transformar-se em poeta". (apud Cit., 309) O autor de Fidalgos $e$ vaqueiros entoa hinos e odes à alma doméstica do homem brasileiro do interior. $\mathrm{O}$ valor da obra é inquestionável, conquanto o narrador repise muito os seus mesmos 
assuntos (a beleza do solo, a vida serena e farta nos solares, a escravidão mais amena, as mesas repletas, a alimentação variada, a boa vida natural do campo, enfim). Do ponto de vista da linguagem, Eurico Alves Boaventura desidrata o texto de Fidalgos e vaqueiros pelo uso abusivo do repetidíssimo adjetivo, o estéril interessante.

No tratamento da cultura literária no ambiente pesquisado, o narrador destaca o gosto pela leitura nas fazendas, de Peres Escrich ao Rocambole e ao Juden errante. Concordando com Taunay (Cf. Memórias, Rio de Janeiro: Bibliex, 1960, p. 142), Eurico descobre em Piquiri um leitor das "Ruinas de Volney e as obras do Barão de Holbach" (apud Cit., 327). A predominância de leituras eram os livros de reza e as obrigatórias viagens de Spix e Martius, livros da época do relato memorial, com destaque para romances, histórias românticas e de aventura e, é claro, a História do imperador Carlos Magno e os doze pares de França (Cit., 327).

Embora repila a noção, ou senso comum, o conceito antropológico sobre a categoria dos coronéis, justificando os crimes como demandas das cidades $(O$ crime é da Capital - Cit., 362), predomina em Fidalgos e vaqueiros um excessivo teor de defesa do universo do pastoreio (em contrapartida, os engenhos concentrariam toda sorte de vícios). Isso culmina no comprometimento do texto e do discurso, tornando o autor um exclusivista da visão única, obliterando um maior potencial de isenção historiográfica. Os coronéis sertanejos são vistos como heróis da saga, abancados num peculiar senso de justiça intimamente partidarizado por Eurico Alves Boaventura. Os senhores são cortejados aristocraticamente, a exemplo dos barões urbanos, todos tidos como homens de prol, com indisputada envergadura moral, tudo conforme o cordel e as impressões de Eurico, para quem "a história dos Coronéis se apresenta bem clara, prendendo desordeiros, castigando desonras femininas". (Cit., 362)

A ojeriza à civilização canavieira faz Eurico Alves Boaventura exorbitar de seu juízo historiográfico e memorial, estendendo o vezo aos poetas dela oriundos: "Açúcar que faz gente suave, macia, que inventa poetas melados de rapadura e melaço". (Cit., 363) A alusão explicita o alvo, o pernambucano Maciel Pinheiro, autor, segundo Boaventura, de imagens vazias, "cor de ponto de cocada branca". (Cit., 363) O poeta e memorialista feirense é cronista orgulhoso da fidalguia suserana ao sol dos sertões, reiteradamente descrevendo foros dessa autonomia e autoridade, detentoras de um prestígio sem conta extensivo aos patriarcas e matriarcas sertanejos, decantados por um de seus mais legítimos egressos.

Não satisfeito, Eurico justifica o jagunço como registro do desequilíbrio orgânico das cidades, que compelem o indivíduo ao crime. Nunca seria, então, resultado das circunstâncias do mítico sertão, território ungido de sacralidade. O que faz o narrador 
de Fidalgos derivar para um juízo suspeito a propósito da Literatura, que Eurico Alves Boaventura considera invenção, fantasia - e isso depreciativamente, como forma negativa de historiar. Não raro, em defesa de suas teses, Eurico deixa sua obra resvalar para um impressionismo quase passional e sempre obstinado. Fala tanto de cabras e jagunços formados na vingança e no desvio da ordem social e nada conta a respeito de Lucas da Feira, embora cite Antônio Silvino, José do Telhado, Jesuíno Brilhante, o Cabeleira e outros protagonistas no cangaço nordestino - ambientado, porém, nas zonas dos canaviais...

Recusando-se a perceber "o pastoreio como estufa para a proliferação do vadio" (Cit., 377), indiretamente associando a malandrice à órbita de urbanidade dos engenhos, Eurico mostra um vaqueiro sertanejo completamente distante do que denomina (e atribui a regiões como a canavieira ou a cacaueira baianas) "a mesma heterogênea poeira de detritos sociais, a poluir a vida de então". (Cit., 377) Talvez porque é crença do autor de Fidalgos e vaqueiros que o meio ultraja o indivíduo, plasmando-lhe uma mentalidade socialmente mórbida (Cit., 352).

Apoiando-se sempre numa relação de contigüidade de seu texto com a memória poética (dos onze capítulos do livro, somente o décimo não vem precedido de uma epígrafe), o relato historiográfico e memorial de Fidalgos e vaqueiros concede à Poética o tônus descritivo e singular da metáfora comparativa. É exemplo dessa hipótese o trecho que descreve o ativo movimento da paisagem sertaneja divisada pelo narrador: "E, escondendo o sol na volúpia noturna do crepúsculo, a Serra de São José das Itapororocas, ao poente da povoança, se levanta como seios túrgidos de tapuia para a última carícia do dia". (Cit., 389) Após o ritmo de ode enaltecedora do parente santo, o padre Ovídio, o último capítulo de Fidalgos e vaqueiros reserva um teor elegíaco no discurso, o relato exprimindo uma evidente notação melancólica ante a mudança de tempo e de paisagem pastoril no universo da região dos currais de Feira de Santana. A metamorfose do pasto, de pastoreio de cria para engorda comercial e industrial, é lamentada por Eurico Alves Boaventura como perda conseqüente da queda de qualidade na paisagem.

\section{$\operatorname{son}$}

\section{REFERÊNCIA:}

BOAVENTURA, Eurico Alves. Fidalgo e vaqueiros. Salvador, UFBA / Centro Editorial e Didático, 1989. 
Fidalgos e vaqueiros: de monumento antropológico a ode do universo agropastoril

Chevaliers and ranchers: from an anthropological monument to and an ode of the agricultural and cattle raising universe

\section{RESUMO}

Estudo da obra ensaística de Eurico Alves Boaventura que se perfila entre a historiografia dos costumes sertanejos, a antropologia social e suas vinculações com as matrizes sociológicas da civilização do couro, cujos aspectos memorialísticos se cotejam e representam na microrregião encabeçada por Feira de Santa.

Palavras-chave: Eurico Alves - sociologia - civilização do couro

\section{ABSTRACT}

Study on the essayistic work of Eurico Alves Boaventura which stands among the historiography of countryside customs, social anthropology and its conections with the sociological matrixes of the leather civilization, whose memorialistic aspects are confronted and represented in the microregion leaded by the city of Feira de Santana.

Key-Words: Eurico Alves - Sociology - leather civilization

Recebido: 17/03/2009

Aprovado: $11 / 06 / 2009$

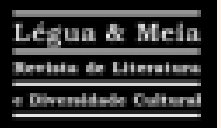

ARAÚJO, Jorge de Souza. Fidalgos e vaqueiros:de monumento antropológico a ode do universo agropastoril. Légua \& meia: Revista de literatura e diversidade cultural. Feira de Santana, UEFS, v. 7, n 5, 2009, p. 7-19.

Jorge de Souza Araújo é Doutor em Letras Vernáculas (UFRJ), com Pós-doutorado (PUC-RJ), é Professor Titular de Literatura Brasileira (UEFS); publicou 25 títulos em poesia, ficção e ensaio, sendo os mais recentes: Floração de imaginários: o romance baiano no século XX (2008); Jorge de Lima, a palavra em pânico (2008) e Graciliano Ramos, o desgosto de ser criatura (2009). Atualmente desenvolve pesquisa e elabora uma enciclopédia da literatura baiana. 